\title{
Prediction of the interacting surfaces in a trimolecular complex formed between the major dust mite allergen Der p 1, a mouse monoclonal anti-Der $\mathrm{p} 1$ antibody, and its anti-idiotype
}

\author{
P B Furtado, R Furmonaviciene, J McElveen, H F Sewell, F Shakib
}

\begin{abstract}
Background-Two mouse monoclonal antibodies (mAbs) have been described recently; namely, mAb $2 \mathrm{C} 7$ (IgG2bк), which is directed against the major house dust mite allergen Der $p$ 1, and mAb 2 G10 (IgG1к), which is an anti-idiotypic antibody raised against $\mathrm{mAb} 2 \mathrm{C} 7$. The antiidiotype $\mathrm{mAb} 2 \mathrm{G} 10$ does not block the binding of $\mathrm{mAb} 2 \mathrm{C} 7$ to Der p 1, which means that $\mathrm{mAb} 2 \mathrm{C} 7$ can simultaneously bind to Der $p 1$ and to $\mathrm{mAb} 2 \mathrm{G} 10$, thereby generating a trimolecular complex consisting of antigen-idiotype-anti-idiotype. Aims-To sequence and model the V region of the anti-idiotypic antibody $\mathrm{mAb}$ 2 G10 to enable the prediction of the interacting surfaces in the trimolecular complex consisting of Der $p$ 1-mAb 2C7-mAb 2 G10.
\end{abstract}

Methods-DNA sequencing of $\mathrm{mAb} 2 \mathrm{G} 10$ was carried out and the Swiss Model and Swiss PDB-Viewer programs were used to build a three dimensional model of the trimolecular complex.

Results-Complementarity of shape and charge was revealed when comparing the protrusion of the previously determined Der p 1 epitope (Leu147-Gln160) with the cavity formed by the complementarity determining regions (CDRs) of $\mathrm{mAb} 2 \mathrm{C} 7$. Such complementarity was also observed between the $\mathrm{mAb} 2 \mathrm{C} 7$ epitope predicted to be recognised by $\mathrm{mAb} 2 \mathrm{G} 10$ (residues Lys19 from framework region 1 (FRW1) and Ser74-Gln81 from FRW3) and residues from the CDRs of mAb $2 \mathrm{G10}$ (a negatively charged patch flanked by the residues Asp55H/Glu58H and Glu27L/ Glu27cL). As expected, the location of the $\mathrm{mAb} 2 \mathrm{C} 7$ epitope recognised by $\mathrm{mAb} 2 \mathrm{G} 10$ does not appear to interfere with the binding of Der $p 1$ to $\mathrm{mAb} 2 \mathrm{C} 7$.

Conclusion-Although the results obtained represent only an approximation, they nevertheless provide a rare insight into how an antigen (Der p 1) might bind to its antibody (mAb 2C7) while in complex with an anti-idiotype (mAb 2G10).

(F Clin Pathol: Mol Pathol 2000;53:324-332)

Keywords: Der p 1; anti-idiotype antibodies; monoclonal antibodies; antigen-antibody binding
We have recently described two mouse monoclonal antibodies; namely, $\mathrm{mAb} 2 \mathrm{C} 7$ (IgG2bK), ${ }^{1}$ which is directed against the major house dust mite allergen Der p 1, and mAb $2 \mathrm{G} 10(\mathrm{IgG} 1 \kappa),{ }^{2}$ which is an anti-idiotypic antibody raised against $\mathrm{mAb} 2 \mathrm{C} 7$. We have established, using phage peptide libraries, that $\mathrm{mAb}$ 2C7 recognises a conformational epitope comprising Leu147-Gln160 within the Der p 1 sequence, ${ }^{3}$ and that this specificity is a major component of the human IgE anti-Der $\mathrm{p} 1$ response. ${ }^{1}$ We have also provided evidence to show that part of the epitope recognised by mAb 2 G10 is a hexapeptide spanning Ser74Tyr79 within the framework 3 (FRW3) region of $\mathrm{mAb} 2 \mathrm{C} 7 .^{2}$

Anti-idiotype mAb $2 \mathrm{G} 10$ appears to be directed against FRW sequences encoded by the $\mathrm{V}_{\mathrm{H}} 3$ and $\mathrm{V}_{\mathrm{H}} 4$ gene families, but its most intriguing property is that it reacts with human IgE regardless of its antigenic specificity. ${ }^{2}$ The fact that mAb $2 \mathrm{G} 10$ binds to the humanised (complementarity determining region (CDR) grafted) CAMPATH-1H antibody, ${ }^{4}$ but not to the original rat CAMPATH-1 YTH34.5.6 antibody, ${ }^{4}$ is further evidence that it is directed against a FRW region, rather than the CDRs. ${ }^{2}$ This is of course in keeping with our observation that mAb 2 G10 does not block the binding of mAb $2 \mathrm{C} 7$ or human $\operatorname{IgE}$ to Der $\mathrm{p}$ $1 .^{2}$ This means that mAb $2 \mathrm{C} 7$ can simultaneously bind to Der p 1 and to mAb 2G10, thereby generating a trimolecular complex consisting of antigen-idiotype-anti-idiotype. This, therefore, raises the question of the relative disposition of these three molecules in this immune complex, which can only be answered with confidence by solving its crystal structure. There have been only four reports describing co-crystals of idiotypeanti-idiotype complexes in the literature..$^{5-8}$ Two of these are based on the anti-idiotype mimicking the antigen and therefore reacting with the CDRs rather than the FRW regions, ${ }^{56}$ and the other two anti-idiotypes recognise CDR and FRW residues. ${ }^{7}$ As mentioned above, mAb $2 \mathrm{G} 10$ recognises only FRW residues, and as such it has a rather special specificity.

Powerful computer packages for three dimensional modelling and molecular docking are currently available. Using the programs Swiss Model $^{910}$ and Swiss PDBViewer, ${ }^{910}$ we have investigated shape and charge complementarity to predict the interacting surfaces in the trimolecular complex
Accepted for publication 5 September 2000 


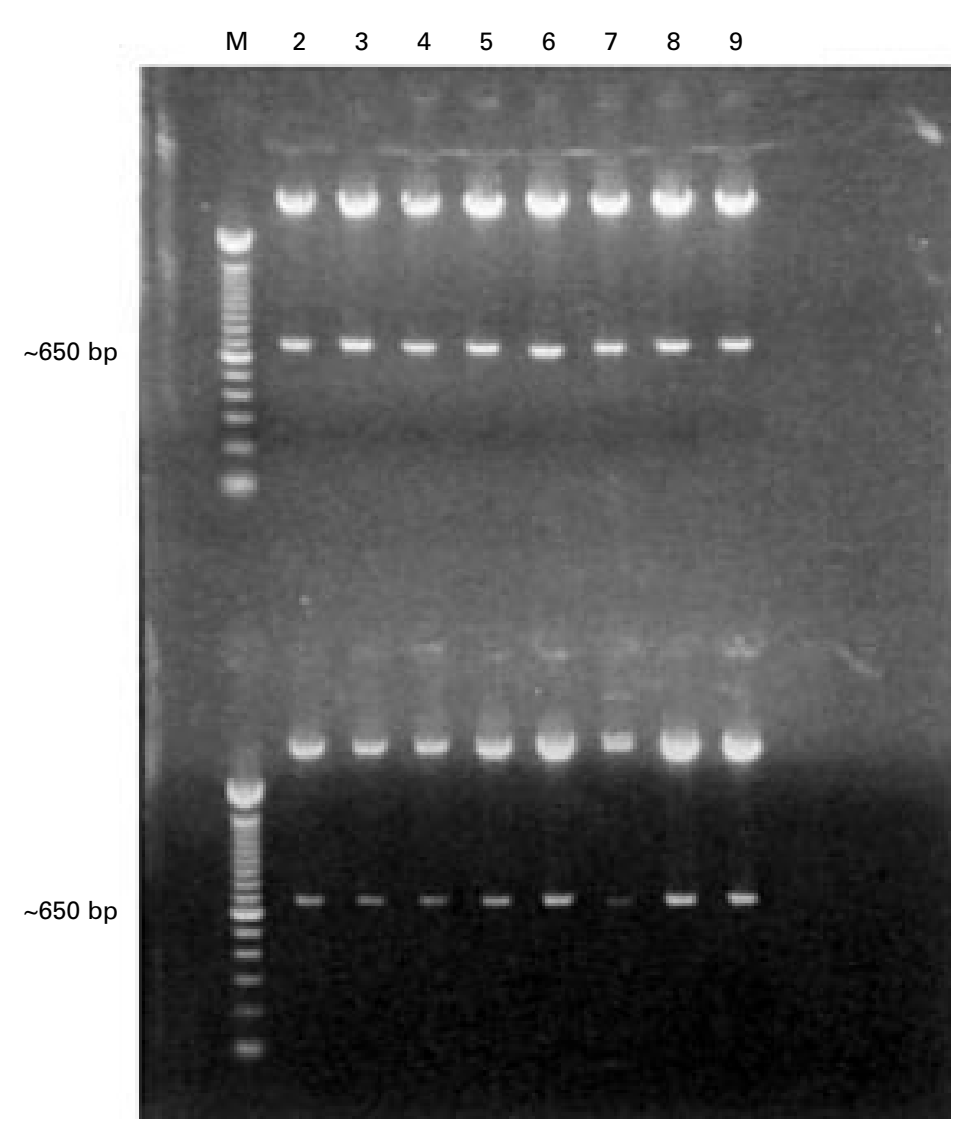

Figure 1 A 1\% agarose gel showing PCR products and restriction digests of plasmids containing the monoclonal antibody $2 G 10 \mathrm{cDNA}$ inserts for the light chain (top lanes 2-9) and the heavy chain Fd fragment (bottom lanes 2-9). Lane M contains a $100 \mathrm{bp}$ ladder.

consisting of Der p 1-mAb 2C7-mAb 2 G10. Although these results are only an approximation, our molecular modelling efforts, combined with our previous experimental data, ${ }^{1-3}$ provide a rare insight into how an antigen might bind to its antibody while in complex with an anti-idiotype.

\section{Materials and methods}

PRODUCTION OF MOUSE MONOCLONAL ANTI-IDIOTYPE 2 G10

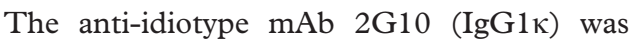
produced and characterised as documented previously. $^{2}$

\section{REVERSE TRANSCRIPTION AND POLYMERASE} CHAIN REACTION (PCR)

Approximately $1 \times 10^{6} \mathrm{mAb} 2 \mathrm{G} 10$ hybridoma cells were harvested by centrifugation and homogenised using a QIASHREDDER ${ }^{\mathrm{TM}}$ column (Qiagen Limited, Dorking, UK). Total RNA was prepared using the Qiagen RNeasy kit according to the manufacturer's instructions. cDNA synthesis was performed by heating $10 \mu \mathrm{l}$ of the total RNA preparation to $70^{\circ} \mathrm{C}$ for five minutes, then placing it on ice and adding $4 \mu \mathrm{l} 5 \times$ Superscript buffer, $0.5 \mu \mathrm{l}$ oligo(dT) primer $(0.5 \mathrm{mg} / \mathrm{ml}$; Pharmacia, Uppsala, Sweden), $2 \mu \mathrm{ldNTP}(5 \mathrm{mM}), 2 \mu \mathrm{l}$ dithiothrietol $(0.1 \mathrm{M}), 0.6 \mu \mathrm{l} \mathrm{RNasin}{ }^{\mathrm{TM}}$ ribonuclease inhibitor ( $40 \mathrm{U} / \mathrm{ml}$; Promega Corporation, Madison, Wisconsin, USA), and $200 \mathrm{U}$ Superscript $\mathrm{II}^{\mathrm{TM}}$ Rnase $\mathrm{H}^{-}$reverse transcriptase (Gibco BRL, Middlesex, UK). This was followed by incubation at $42^{\circ} \mathrm{C}$ for one hour.

PCR was performed as described, ${ }^{11}$ using $1 \mu \mathrm{l}$ of cDNA in each reaction and the primers documented elsewhere ${ }^{11}$ to amplify the complete $\kappa$ chain cDNA and the heavy chain Fd fragment cDNA. PCR products were run on a $1 \%$ agarose gel containing ethidium bromide $(0.2 \mu \mathrm{g} / \mathrm{ml})$ and the DNA was visualised using an ultraviolet transilluminator. Molecular weight markers were a $100 \mathrm{bp}$ DNA ladder (Promega Corporation).

\section{CLONING PCR PRODUCTS}

Ligation was performed using a TA cloning kit (Invitrogen, San Diego, California, USA) with the $\mathrm{pCR}^{\mathrm{TM}} 2.1$ plasmid. Transformation of INV $\alpha F^{\prime}$ One Shot ${ }^{\mathrm{TM}}$ competent cells was carried out by heat shock. All procedures were carried out according to the manufacturer's instructions. Transformed cells were selected on the basis of blue/white colour selection in the presence of X-gal. Plasmid DNA was purified from $3 \mathrm{ml}$ overnight cultures in Luria-Bertani (LB) medium containing ampicillin and methicillin (20 and $80 \mu \mathrm{g} / \mathrm{ml}$, respectively), using QIA prep spin miniprep kit (Qiagen Limited). Purified plasmid was digested with EcoRI to check for the presence of an insert of the correct size. The restriction digest was analysed on a $1 \%$ agarose gel.

\section{DNA SEQUENCING}

Automated DNA sequencing was carried out on an ABI PRISM 310 genetic analyser, using the ABI PRISM dye terminator cycle sequencing ready reaction kit (Perkin-Elmer Applied Biosystems, Warrington, UK).

2 G10 NIVLTQFPTSLAVSPGORATISCRASESVEYFGTGLMOWYOOKPGOPPKLLIYTASNVESGVPARFSGSGSGTDFNLNIHPVEEDDIAMYFCOOSRKVPSTFGGGTRLEIKR 1 MF 2 DT----S-A-----L---------D-Y-KSF-N-F--KSF-H--- $1 \mathrm{GGB}$ D-C-S-G---

$2 G 10$ DVQLVQSGPELVKPGAAVKMSCRASGYTFTSHVMHWVKQKPGQGLEWIGY INPYNDYSENNEKFKDKATLTSDTSSSTAYMELNSLTSEDSAVYYCAKAGYNN . .YYAMEYWGOGTSVTVS IAE6 QI--Q-----------S--I--K-------DYYIN-M-------------W-D-GSGNTKY------G------V----------Q-S-------T--- F--REKTTY . - ----D-----------IFBI Q---Q-P-A-------S--L--K---------YW-------G----------E-D-SDS-PNY------G------V-K--------Q-S--------------SLY-YGTS-GVLD------------

Figure 2 Sequence alignments of the monoclonal antibody $2 G 10 V_{L}$ (top panel) and $V_{H}$ (bottom panel) regions with homologous $V_{L}$ (1MF2, ${ }^{30} 1 A C Y,^{33}$ and $\left.1 \mathrm{GGB}^{34}\right)$ and $V_{H}\left(1 \mathrm{AE} 6{ }^{31} 1 \mathrm{PLG},{ }^{35}\right.$ and $\left.1 \mathrm{FBI}^{36}\right)$ sequences having structural coordinates available within the protein databank. ${ }^{18}$ Complementarity determining regions (CDRs) are indicated by solid lines above the sequences; dots indicate missing amino acids. 
Table 1 Canonical structure classification of the hypervariable loop regions of monoclonal antibody $2 G 10^{2} V_{L}$ and $V_{H}$ according to Clothia and co-workers, ${ }^{37}$ showing sequence similarities with known antibody structures (McP603, ${ }^{42} \mathrm{HyHeL} 45,{ }^{40}$ and $\mathrm{NC} 41^{41}$ )

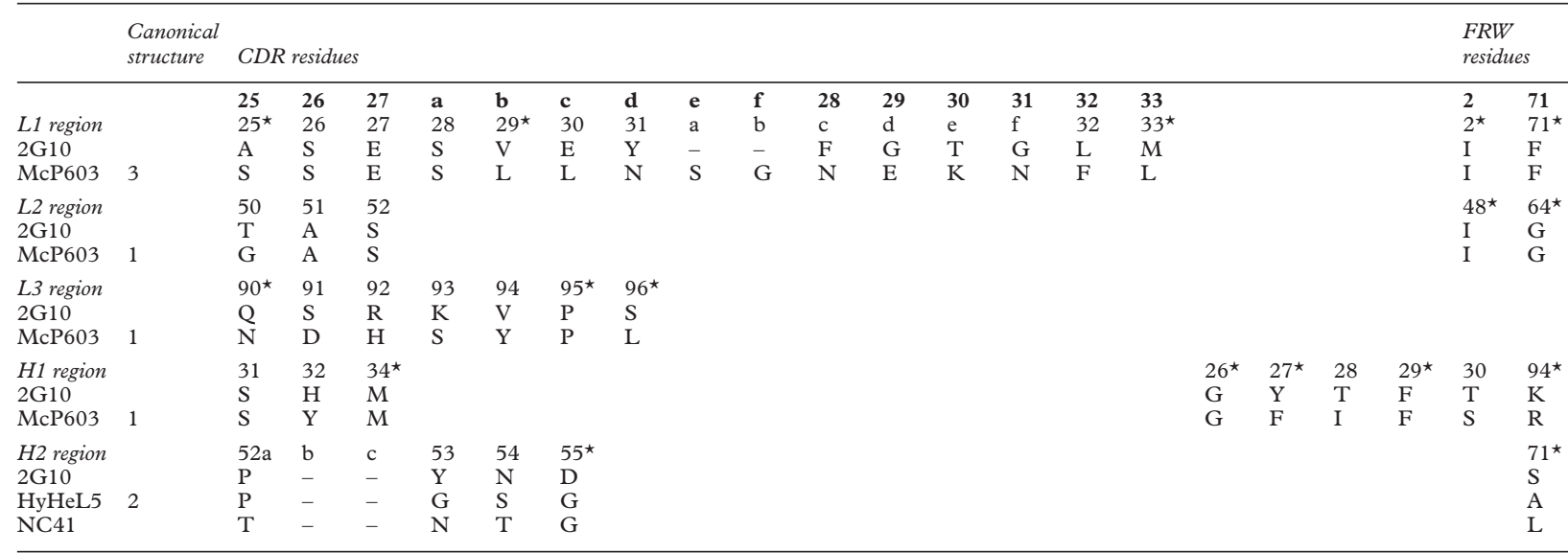

Apart from the L1 region, the Kabat ${ }^{13}$ and Clothia ${ }^{37}$ systems agree in terms of amino acid numbering of the hypervariable loop regions.

Numbers in bold represent residue positions according to the Kabat system. ${ }^{13}$

*Canonical determinants.

FRW, framework region.

SEQUENCE ANALYSIS OF mAb 2 G10

The mAb 2G10 heavy and light chain $\mathrm{V}$ region sequences were compared with murine nucleotide sequences using DNAPLOT, which is available at the International ImMunoGeneTics database (http://imgt.cines.fr:8104). ${ }^{12}$ Sequence numbering was done according to the Kabat system. ${ }^{13}$

SEQUENCE ANALYSIS OF ANTIBODIES TESTED FOR REACTIVITY WITH MAb 2 G10

Comparison of the mAb $2 \mathrm{C} 7 \mathrm{~V}$ region sequence with those of antibodies tested for reactivity with $\mathrm{mAb} 2 \mathrm{G} 10^{2}$ was carried out using Gene Doc (Nicholas KB, Nicholas HBJr, 1997, Gene Doc: analysis and visualisation of genetic variation, http:/www.cris.com/ ketchup/ genedoc.shtml).

\section{MOLECULAR MODELLING}

We have previously described molecular modelling of mAb 2C7. ${ }^{1}$ Molecular models of $\mathrm{mAbs}$ CAMPATH- $1 \mathrm{H}^{4}$ (1BEY), ${ }^{14}$ CAMPATH-1H YTH34.5.6 $6^{4}$ (1BFO), ${ }^{14}$ and MOPC-2 $1^{15}{ }^{16}(1 \mathrm{IGC})^{17}$ were available from the protein databank (PDB). ${ }^{18}$ Modelling of mAbs $105 \mathrm{AD} 7,{ }^{19} \mathrm{~A} 2,^{20}{ }^{21} \mathrm{Cal}-4 \mathrm{G}^{22}{ }^{23}$ and MOPC- $141^{24} 25$ were based on the following

Table 2 Sequence analysis of the FRW1 and FRW3 regions of monoclonal antibodies ( $m A b s)$ tested for reactivity with $m A b 2 G 10$

\begin{tabular}{|c|c|c|c|c|c|c|c|c|c|c|c|}
\hline \multirow[b]{2}{*}{ Antibody } & \multicolumn{9}{|c|}{ Heavy chain } & \multirow{2}{*}{$\begin{array}{l}\text { Reactivity } \\
\text { with } m A b \\
2 G 10\end{array}$} & \multirow[b]{2}{*}{ Refs } \\
\hline & $F R W 1$ & $F R$ & & & & & & & & & \\
\hline & 19 & 74 & & & & & & & 81 & & \\
\hline $2 \mathrm{C} 7$ & $\mathbf{K}$ & S & $\mathbf{K}$ & $\mathbf{N}$ & $\mathbf{T}$ & $\mathrm{L}$ & $\mathbf{Y}$ & $\mathrm{L}$ & $\mathbf{Q}$ & + & 1 \\
\hline Cal-4G & $\mathbf{S}$ & $\mathbf{S}$ & $\mathbf{K}$ & $\mathbf{N}$ & $\mathbf{Q}$ & $\mathrm{F}$ & S & $\mathrm{L}$ & K & + & 22,23 \\
\hline A2 & $\mathbf{R}$ & $\mathbf{S}$ & $\mathbf{K}$ & $\mathbf{N}$ & $\mathbf{T}$ & $\mathrm{L}$ & $\mathbf{Y}$ & $\mathrm{L}$ & $\mathbf{Q}$ & + & 20,21 \\
\hline САMРАTH-1H & $\mathbf{S}$ & $\mathbf{S}$ & $\mathbf{K}$ & $\mathbf{N}$ & $\mathbf{Q}$ & $\mathrm{F}$ & S & $\mathrm{L}$ & $\mathbf{R}$ & + & 4 \\
\hline $105 \mathrm{AD} 7$ & $\mathbf{T}$ & $\mathbf{S}$ & $\mathbf{K}$ & $\mathbf{N}$ & $\mathbf{Q}$ & $\mathrm{V}$ & $\mathrm{V}$ & $\mathrm{L}$ & $\mathbf{T}$ & - & 19 \\
\hline MOPC-21 & $\mathbf{K}$ & $\mathrm{P}$ & $\mathbf{K}$ & $\mathbf{N}$ & $\mathbf{T}$ & $\mathrm{L}$ & $\mathrm{F}$ & $\mathrm{L}$ & $\mathbf{Q}$ & - & 15,16 \\
\hline MOPC-141 & $\mathbf{S}$ & $\mathbf{S}$ & $\mathbf{K}$ & $\mathbf{S}$ & $\mathbf{Q}$ & V & $\mathrm{F}$ & $\mathrm{L}$ & $\mathbf{k}$ & - & 24,25 \\
\hline YTH34.5.6 & $\mathbf{R}$ & $\mathbf{T}$ & $\mathbf{Q}$ & $\mathbf{N}$ & $\vec{M}$ & $\mathrm{~L}$ & $\mathbf{Y}$ & $\bar{L}$ & $\mathbf{Q}$ & - & 4 \\
\hline
\end{tabular}

Differences in shape and polarity of residues at positions 19 and 74-81 may hinder reactivity with $\mathrm{mAb} 2 \mathrm{G} 10$.

Polar amino acids are shown in bold.

FRW, framework region. templates that are available from the $\mathrm{PDB}^{18}$ : $1 \mathrm{FVD},{ }^{26} 1 \mathrm{HOU},{ }^{27} 7 \mathrm{FAB},{ }^{28}$ and $1 \mathrm{OAK} .{ }^{29} \mathrm{Mod}-$ elling of $\mathrm{mAb} 2 \mathrm{G} 10^{2} \mathrm{~V}_{\mathrm{L}}$ and $\mathrm{V}_{\mathrm{H}}$ was based on $1 \mathrm{MF}^{30}$ and $1 \mathrm{AE} 6,{ }^{31}$ respectively. All modellings were carried out using Swiss Model $^{9}{ }^{10}$ and were viewed using Swiss PDB-Viewer. ${ }^{9}{ }^{10}$ Molecular modelling of Der $p 1$ has been described previously, ${ }^{32}$ and the Der $\mathrm{p} 1$ epitope (Leu 147-Gln 160) recognised by mAb 2C7 has been reported by us elsewhere.

\section{Results}

PCR PRODUCTS AND CLONING

PCR amplification of mAb 2G10 cDNA, using the light and heavy chain primers, in conjunction with the reverse $\kappa$ and $\gamma$ chain primers, resulted in a single band of approximately $650 \mathrm{bp}$ with $\mathrm{V}_{\mathrm{k}}$ frlb and $\mathrm{V}_{\mathrm{H}}$ frlg, respectively. These products were cloned into the vector $\mathrm{pCR}^{\mathrm{TM}} 2.1$ and 10 clones from each reaction were selected for restriction analysis of the plasmids. Figure 1 shows the results of this analysis for eight representative clones for the heavy chain and eight for the $\kappa$ chain.

SEQUENCE ANALYSIS OF mAb 2G10

Figure 2 shows the cDNA deduced protein sequences of the light and heavy chains of $\mathrm{mAb} 2 \mathrm{G} 10$. These are the sequences of individual clones that were identified as containing no PCR errors by comparison with other clones and with the Kabat database. ${ }^{13}$ The first eight amino acids of the light chain and the first nine of the heavy chain were determined by the degenerate primers used for PCR. ${ }^{11}$ The mAb 2G10 heavy and light chain $\mathrm{V}$ region sequences showed the greatest homology with members of the IGHV1 and IGKV3 murine gene families, respectively. According to the Kabat system, ${ }^{13}$ mAb $2 \mathrm{G} 10$ $\mathrm{V}_{\mathrm{L}}$ has an insertion of four residues, 27a to $27 \mathrm{~d}$, in the first hypervariable region (L-CDR1). Insertions of one residue, 52a, and three residues, $100 \mathrm{a}$ to $100 \mathrm{c}$, occur in the second (H-CDR2) and third (H-CDR3) 


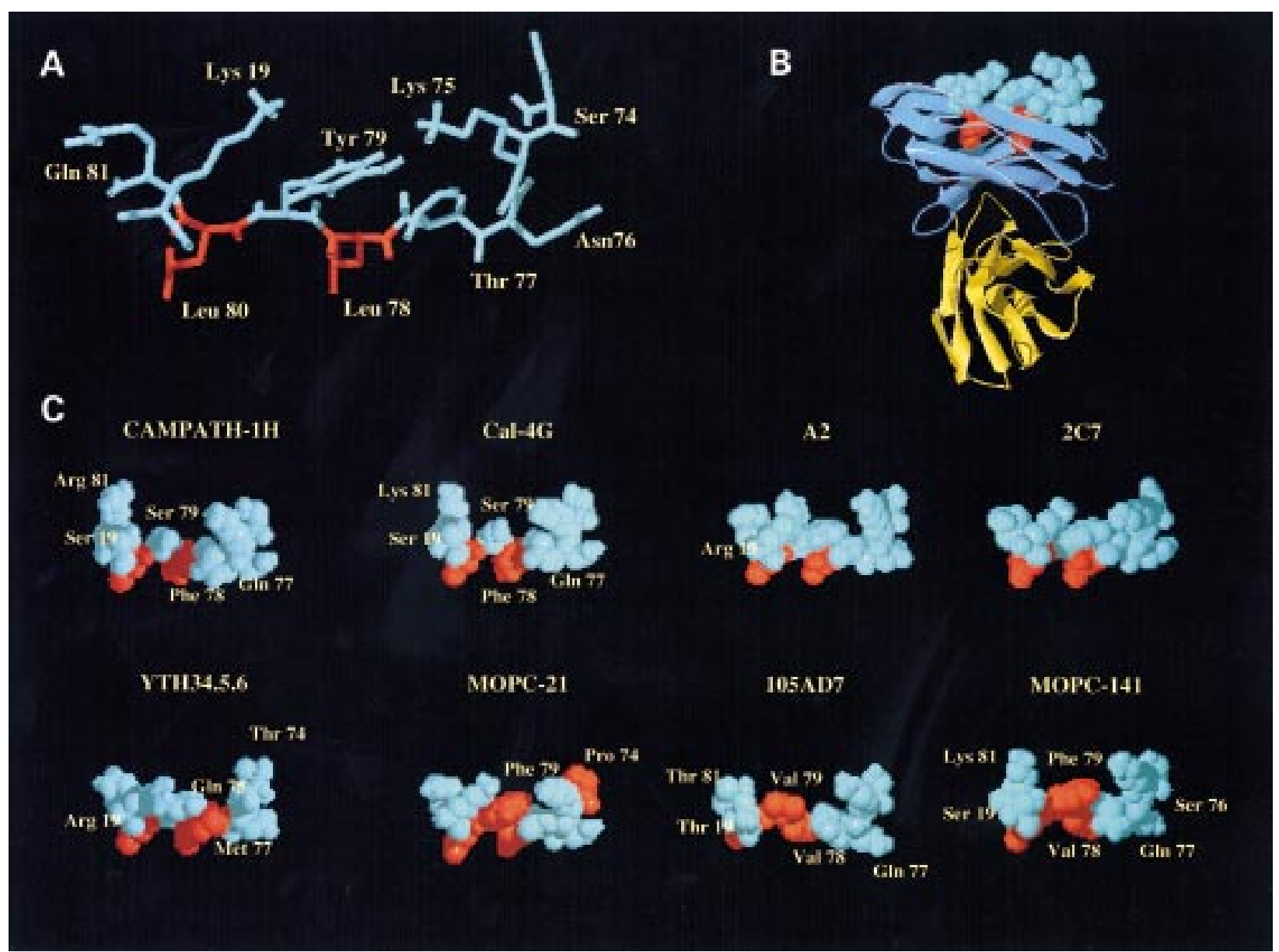

Figure 3 (A) The predicted epitope on monoclonal antibody $(m A b) 2 C 7$ recognised by $m A b$ 2G10, shown in backbone representation (polar residues are shown in cyano blue and non-polar rersidues in red). (B) Side view of the Fv region of $m A b 2 C 7$ showing the location of the predicted epitope on framework region 3 (FRW3) of $V_{H}$ (dark blue). (C) Differences in shape and polarity (shown in space filling representation) between $m A b 2 G 10$ reactive (upper row) and non-reactive (lower row) antibodies. Amino acids that are different from those of $m A b 2 C 7$ are highlighted

hypervariable regions of the mAb $2 \mathrm{G} 10 \mathrm{~V}_{\mathrm{H}}$, respectively. Analysis of the FRW regions showed the presence of an insertion of three residues, $82 \mathrm{a}$ to $82 \mathrm{c}$, in the FRW3 region of $\mathrm{mAb} 2 \mathrm{G} 10 \mathrm{~V}_{\mathrm{H}}$. No insertions or deletions were found in the other FRW regions or in L-CDR2, L-CDR3, and H-CDR1 (fig 2).

CANONICAL STRUCTURE ANALYSIS OF THE MAb 2 G10 HYPERVARIABLE LOOP REGIONS

Analysis of the hypervariable loop regions was performed according to the canonical structure hypothesis of Clothia and co-workers. ${ }^{37}$ The L1 region is formed by residues Ala25 to Met33 from L-CDR1 and FRW residues Ile2 and Phe71, corresponding to the canonical structure $3 .^{37}$ The L2 region involves residues Thr50, Ala51, and Ser52 from L-CDR2 and FRW residues Ile48 and Gly64, and adopts the unique conformation seen among all other structures reported previously. ${ }^{38}$ The L 3 region involves residues Gln90, Ser91, Arg92, Lys93, Va194, Pro95, and Ser96, and is most closely related to the canonical structure 1 . The $\mathrm{H} 1$ region involves $\mathrm{H}-\mathrm{CDR} 1$ residues Ser31, His32, and Met34 and FRW residues Gly26, Tyr27, Thr28, Phe29, Thr30, and Lys94, and is similar to the canonical structure 1 . The $\mathrm{H} 2$ region is defined by residues at positions $52 \mathrm{a} / 53$ to 55 , and a major determinant of its conformation is the FRW residue at position 71. ${ }^{39}$ Thus, the $\mathrm{mAb} 2 \mathrm{G} 10 \mathrm{H} 2$ region (Pro52a, Tyr53, Asn54, Asp55, and Ser71) can be compared with mAbs HyHel $45^{40}$ and $\mathrm{NC} 41,{ }^{41}$ corresponding to the canonical structure 2 , which allows the presence of a small or medium size residue at position $71 .^{39}$ The L1, L2, L3, and $\mathrm{H} 1$ regions of $\mathrm{mAb} 2 \mathrm{G} 10$ have the same canonical structure as mouse mAb McP603. ${ }^{42}$ Despite recent progress, ${ }^{43}$ the conformation of the $\mathrm{H} 3$ region has not yet been fully classified, therefore leading to major uncertainties concerning the orientation of the mAb $2 \mathrm{G} 10$ $\mathrm{H}-\mathrm{CDR} 3$. Table 1 shows the canonical structure classification of the mAb 2G10 hypervariable loop regions.

A MOLECULAR MODEL OF THE VARIABLE REGION OF mAb $2 \mathrm{G} 10$

A predicted three dimensional structure of the $\mathrm{mAb} 2 \mathrm{G} 10 \mathrm{Fv}$ (fragment variable) region was constructed by modelling on homologous structures within the PDB. ${ }^{18}$ A search of the PDB database was performed using the BLAST network service at NCBI, and this produced several structures with reasonable homology to the mAb $2 \mathrm{G} 10$ light chain $\left(1 \mathrm{MF} 2{ }^{30} 1 \mathrm{ACY},{ }^{33}\right.$ and $\left.1 \mathrm{GGB}^{34}\right)$ and heavy chain $\left(1 \mathrm{AE} 6,{ }^{31} 1 \mathrm{PLG},{ }^{35}\right.$ and $1 \mathrm{FBI}^{36}$ ) (fig 2). $1 \mathrm{MF} 2 \quad(\mathrm{~F} 11.2 .32),{ }^{30}$ 1ACY $(59.1),{ }^{33}$ and 


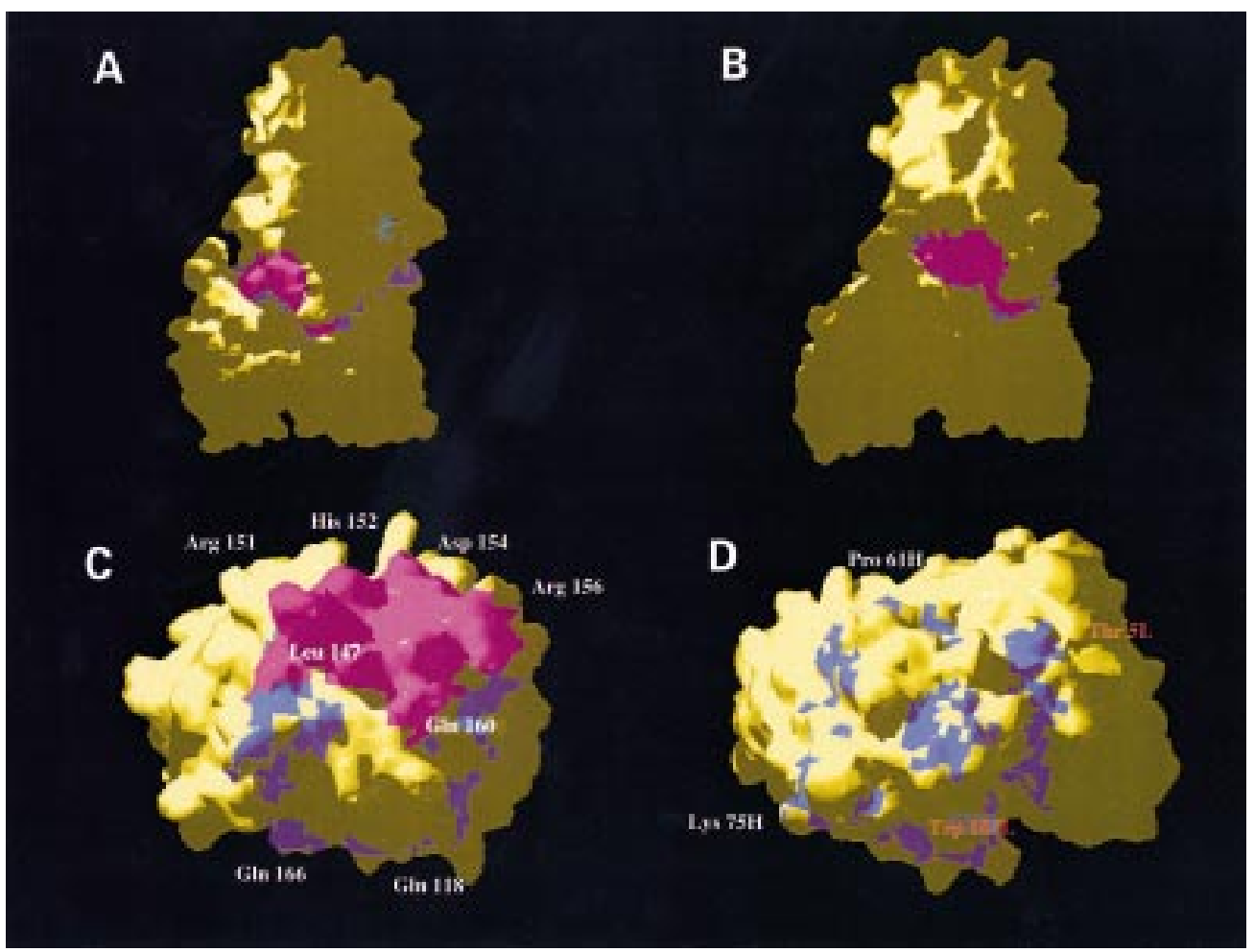

Figure 4 (A) Front and (B) side views of the Derp 1-mAb $2 C 7$ complex showing shape complementarity between the Der $p$ 1 (top structure) epitope recognised by monoclonal antibody ( $m A b) 2 C 7$ (Leu147-Gln160) ${ }^{3}$ and the Fv region of $m A b 2 C 7$ (lower structure). The contacting surfaces between (C) Der $p 1$ and (D) $m A b 2 C 7$ are defined by a quadrangular patch (blue), which in Der $p 1$ is surrounded by residues Arg151, Arg156, Gln118, and Gln166 and in $m A b 2 C 7$ by residues Pro61H, Thr5L, Trp103H, and Lys 75H. The previously determined epitope for mAb 2C7 on Der $p 1$ is shown in purple.

1GGB $(50.1)^{34}$ are all murine monoclonal antihuman immunodeficiency virus antibodies. Sequence analysis of L-CDR1 showed that $\mathrm{mAb} 2 \mathrm{G} 10$ has greater homology with F11.2.32 and 59.1 than with 50.1. Although L-CDR1 of F11.2.32 has only one amino acid difference when compared with 59.1 (TyrL27d $\rightarrow$ Ser), a Tyr at this position was shown to cause structural differences in L-CDR1 affecting antigen recognition. ${ }^{30} \mathrm{Be}-$ cause mAb 2G10 also has TyrL27d, modelling of its light chain was based on F11.2.32 $\mathrm{V}_{\mathrm{L}}$, which also belongs to the murine VK3 subgroup and corresponds to the same canonical classification as mAb $2 \mathrm{G} 10 \mathrm{~L}$ regions $^{30}$ (fig 2). Another template was chosen for modelling the $\mathrm{V}_{\mathrm{H}}$ region of $\mathrm{mAb} 2 \mathrm{G} 10$, because $\mathrm{F} 11.2 .32$ does not have the same length and canonical structure classification as the mAb $2 \mathrm{G} 10 \mathrm{H} 2$ and $\mathrm{H} 3$ loop regions. ${ }^{30}$ Thus, modelling of the $\mathrm{mAb} 2 \mathrm{G} 10 \mathrm{~V}_{\mathrm{H}}$ region was based on 1AE6 (antitumour mAb CTM01), ${ }^{31}$ which shows sequence similarities and has the same loop length ( $\mathrm{H} 3$ region inclusive) compared with the other homologous structures $\left(1 \mathrm{PLG}^{35}\right.$ and $1 \mathrm{FBI}^{36}$ ) (fig 2). The models were built using Swiss Model $^{9}{ }^{10}$ and viewed using Swiss PDBViewer $^{910}$

ANALYSIS OF THE MOLECULAR MODELS OF ANTIBODIES THAT WERE TESTED FOR REACTIVITY WITH mAb 2 G10

Competitive inhibition studies previously confirmed that mAb $2 \mathrm{G} 10$ is most likely to be directed against FRW regions encoded by the $\mathrm{V}_{\mathrm{H}} 3$ and $\mathrm{V}_{\mathrm{H}} 4$ genes. $^{2}$ It is known that codons
6-24 in FRW1 and 67-85 in FRW3 are highly conserved among sequences within a single $\mathrm{V}_{\mathrm{H}}$ family, but diverge when compared with different $\mathrm{V}_{\mathrm{H}}$ families. ${ }^{44}$ The variation of these sequences in FRW1 and FRW3 is considerably smaller when comparing mouse and human $\mathrm{V}_{\mathrm{H}} 3$ gene segments. ${ }^{44}$ Considering that $\mathrm{mAb}$ $2 \mathrm{C} 7$ is a member of the $\mathrm{X}-24$ mouse family, and this family shows up to $70 \%$ homology with the human $\mathrm{V}_{\mathrm{H}} 3$ family, ${ }^{1}$ we speculate that sequence variation affecting polarity and structure within FRW1 and FRW3 might explain differential reactivity with $\mathrm{mAb} 2 \mathrm{G} 10$ (table 2 ). We have already reported the sequence spanning amino acids $74-79$ within FRW 3 as being part of the epitope recognised by mAb $2 \mathrm{G} 10 .{ }^{2}$ Comparison of the three dimensional models of the mAb $2 \mathrm{G} 10$ reactive and non-reactive antibodies, using Swiss Model $^{9}{ }^{10}$ and Swiss PDB-Viewer, ${ }^{910}$ showed differences in structure and polarity of the side chains of amino acid residues spanning positions 74-81 within FRW3 and at position 19 in FRW1. It seems that the mAb $2 \mathrm{C} 7$ epitope recognised by $\mathrm{mAb}$ $2 \mathrm{G} 10$ is a protrusion consisting of polar amino acids Ser74-Gln81 and Lys19 (fig 3). In mAbs Cal- $4 \mathrm{G}^{22}{ }^{23}$ and CAMPATH- $1 \mathrm{H},{ }^{4}$ which were reactive with $\mathrm{mAb} 2 \mathrm{G} 10$, the lack of a positively charged amino acid (Lys/Arg $\rightarrow$ Ser) in position 19 seems to be structurally compensated for by the presence of a positively charged amino acid at position 81 (Gln $\rightarrow$ Lys/ Arg). Monoclonal antibodies 105AD7, ${ }^{19}$ MOPC-21, ${ }^{15} 16$ and MOPC-141, ${ }^{24}$ which were not reactive with $\mathrm{mAb} 2 \mathrm{G} 10,{ }^{2}$ all have non-polar, rather than polar, residues in 
position 79 (Val or Phe), which might lead to loss of reactivity. Monoclonal antibody $105 \mathrm{AD} 7^{19}$ has a polar amino acid (Thr) at positions 19 and 81, which might hinder reactivity with $\mathrm{mAb} 2 \mathrm{G} 10$. Moreover, $\mathrm{mAb}$ MOPC- $21^{12}{ }^{13}$ has a non-polar residue in position 74, namely Pro, that might also influence its reactivity with $\mathrm{mAb} 2 \mathrm{G} 10,{ }^{2}$ because Ser in this position appears to be highly conserved in $\mathrm{mAb} 2 \mathrm{G} 10$ reactive antibodies from the $\mathrm{V}_{\mathrm{H}} 3$ and $\mathrm{V}_{\mathrm{H}} 4$ gene families. In the original rat CAMPATH-1H YTH34.5.6 antibody, ${ }^{4}$ the presence of Gln, instead of Lys, in position 75 and of a non-polar residue in position 77 (Met), instead of a polar residue ( $\mathrm{Thr} / \mathrm{Gln}$ ), might explain the lack of reactivity with $\mathrm{mAb}$ 2G10 (table 2; fig 3).

ANALYSIS OF THE MOLECULAR INTERACTIONS WITHIN THE TRIMOLECULAR COMPLEX Der $\mathrm{p}$ 1-mAb 2C7-mAb $2 \mathrm{G} 10$

The Der $\mathrm{p} 1$ epitope recognised by mAb $2 \mathrm{C} 7$ was previously determined using phage display libraries and was shown to be a conformational sequence comprising Leu147-Gln $160 .^{3}$ Possible interacting surfaces between $\mathrm{mAb} 2 \mathrm{C} 7$ and Der $\mathrm{p} 1$ were predicted by analysing the complementarity in charge and structure between the previously determined Der $\mathrm{p} 1$ epitope Leu 147-Gln $160^{3}$ and $\mathrm{mAb} 2 \mathrm{C} 7 \mathrm{CDRs}$ using Swiss PDB-Viewer. ${ }^{9}{ }^{10}$ Analysis of the molecular model of the complex formed between Der $\mathrm{p} 1^{3}$ and $\mathrm{mAb} 2 \mathrm{C} 7^{1}$ revealed a high degree of surface complementarity (fig 4). The Der $\mathrm{p} 1$ surface contacting mAb $2 \mathrm{C} 7$ consists of four residues forming a quadrangle; namely, Arg151, Arg156, Gln118, and Gin166. The complementary quadrangle on $\mathrm{mAb} 2 \mathrm{C} 7$ is formed by residues Pro61H, Thr5L, Trp $103 \mathrm{H}$, and Lys75H. The previously determined Der p 1 epitope (Leu147$\mathrm{G} \ln 160)^{3}$ forms the most protruding part of the Der $\mathrm{p} 1$ surface involved in the interaction with $\mathrm{mAb} 2 \mathrm{C} 7$. Such protrusion from the Der $\mathrm{p} 1$ surface appears to fit into a cavity formed by the CDRs of mAb 2C7 and defined by the solvent accessible triad Lys64H, Arg24L, and Arg97H. The interacting surfaces between $\mathrm{mAb} 2 \mathrm{C} 7$ and Der p 1 also revealed complementary electrostatic potential (fig 5). The $\mathrm{mAb} 2 \mathrm{C} 7$ contacting surface on Der $\mathrm{p} 1$ is formed by a patch of negatively charged residues surrounded by four positively charged residues; namely, Arg151, Arg156, Arg161, and Lys 145 . This negatively charged patch is met on the mAb $2 \mathrm{C} 7$ surface by a positively charged area surrounded by the negatively charged residues Asp53H, Asp53L, and Asp28H. The positively charged Der $p 1$ residues Arg156 and Arg161 are complementary to the negatively charged $\mathrm{mAb} 2 \mathrm{C} 7$ residues Asp53H and Asp28H, respectively. The protruding Der $\mathrm{p} 1$ residues Lys145 and Arg151 fit into two cavities formed between the

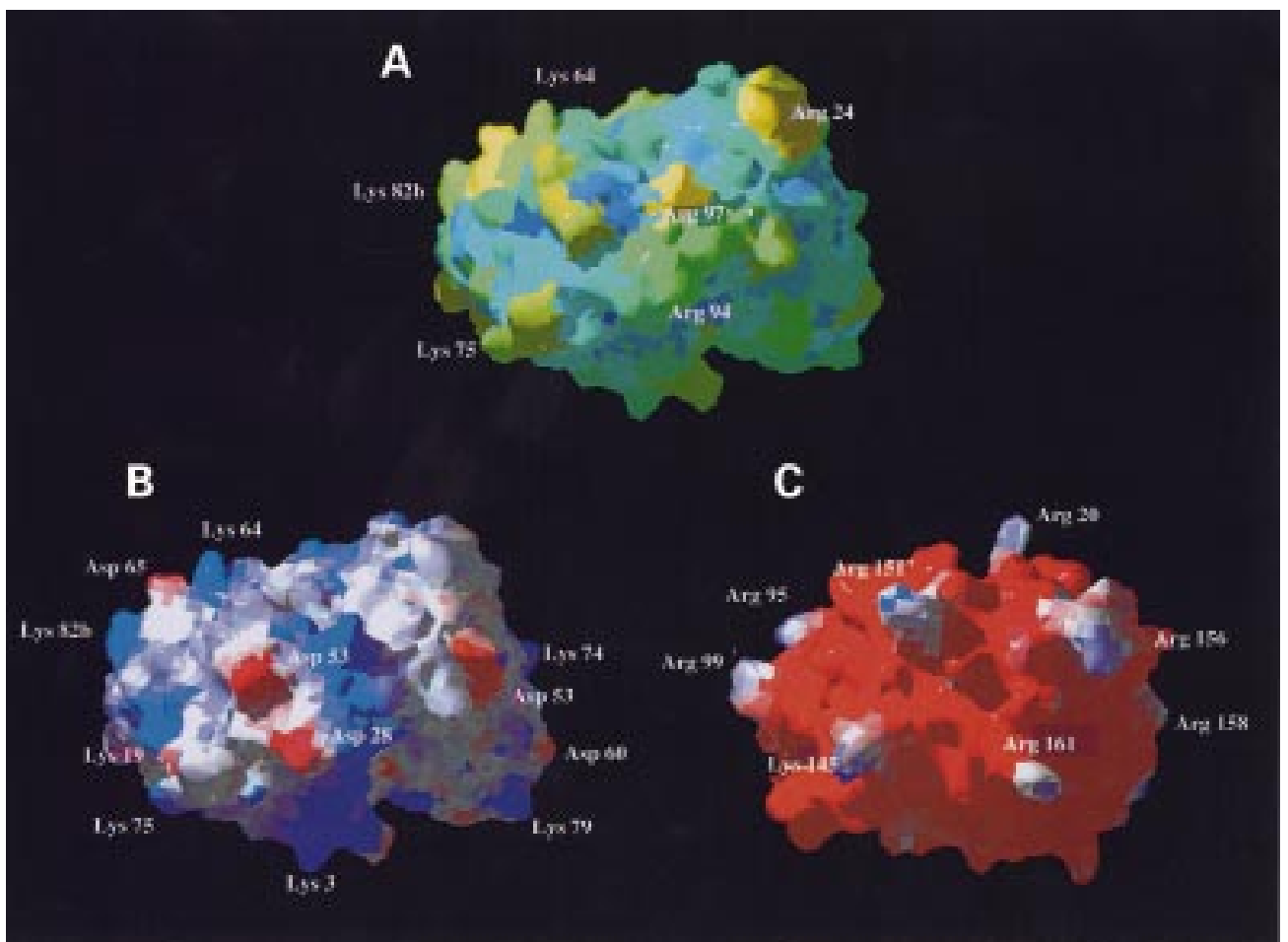

Figure 5 Complementarity of $(A)$ shape and $(B$ and $C$ ) electrostatic potential between the monoclonal antibody (mAb) $2 C 7$ epitope on Der $p 1$ and the Fv region of $m A b 2 C 7$. The protrusion formed by the Der $p 1$ epitope (Leu147-Gln160) fits into the cavity defined by the solvent accessible residues (Lys64H, Arg24L, and Arg97H) of the complementarity determining regions (CDRs) of $m A b$ 2C7. Complementarity of electrostatic potential between $m A b 2 C 7$ (a negatively charged patch defined by residues Asp53H, Asp53L, and Asp28H) (B) and Derp 1 (a positively charged patch defined by residues Arg151, Arg156, Arg161, and Lys 145) (C) is shown in red and blue, respectively. The $m A b 2 C 7$ residues Asp53H and Asp28H (B) are complementary to the Derp 1 residues Arg156 and Arg161 (C), respectively. The protruding Der $p 1$ residues Lys 145 and Arg151 fit into two cavities formed between the $m A b 2 C 7$ residues $A s p 28 H$ and $A s p 53 H$ on one side and Asp28H, Asp53H, and Asp53L on the other side. The Fv region of $m A b 2 C 7(A)$ is coloured according to solvent accessibility, decreasing in the order yellow, green, light blue, and dark blue. The electrostatic potential was computed by the program Swiss PDB-Viewer, ${ }^{10}$ which uses simple coulomb interaction. 


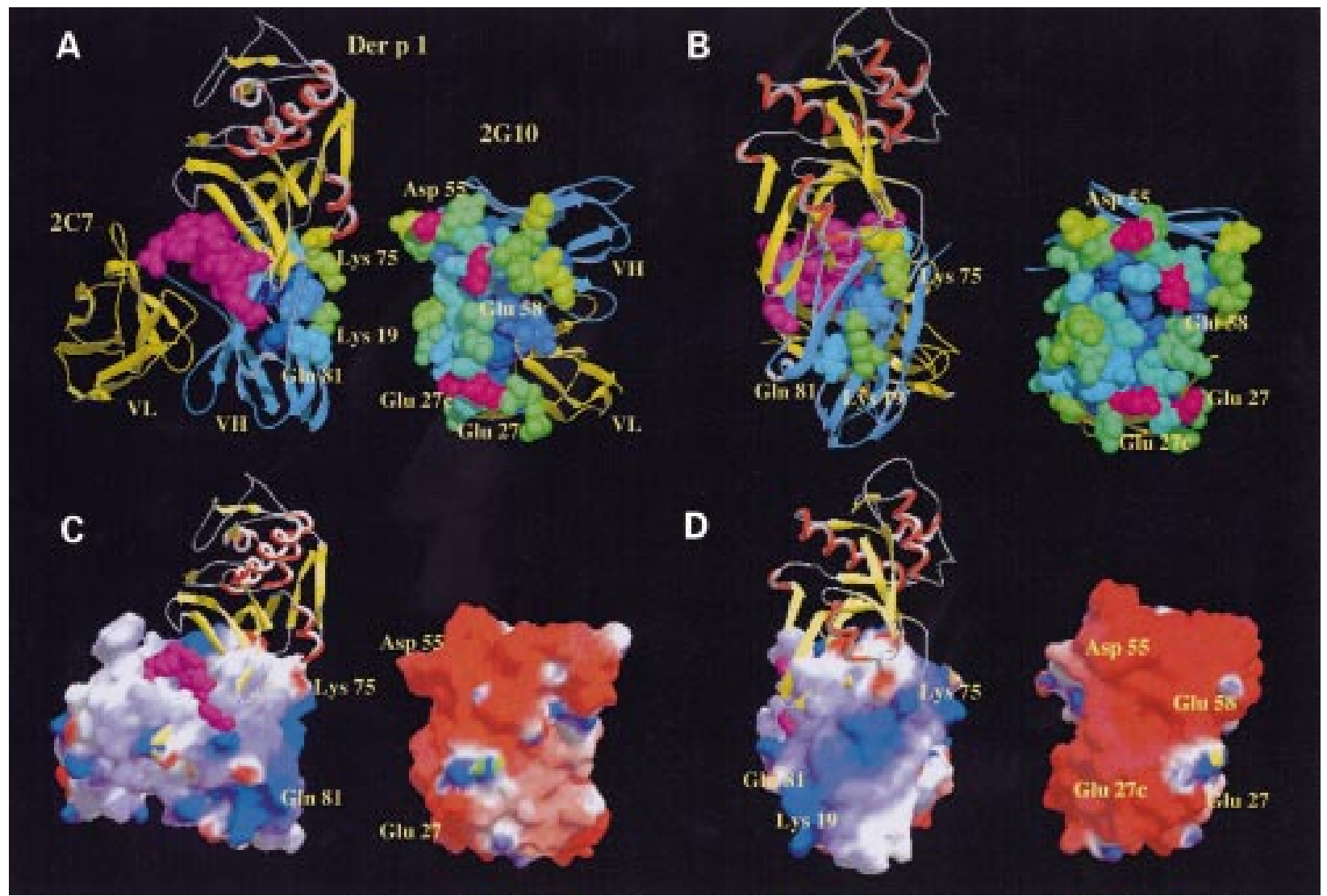

Figure 6 A molecular model of the trimolecular complex consisting of Der p1-monoclonal antibody (mAb) 2C7-mAb 2G10. The previously determined Der $p 1$ epitope recognised by $m A b 2 C 7$ (Leu147-Gln160), ${ }^{3}$ shown in space filling representation (purple). The mAb 2C7 epitope predicted to be recognised by $m A b 2$ G10 forms a protrusion, involving residues Ser74-Gln81 (framework region 3 (FRW3)) and Lys19 (FRW1), which fits into a cavity, defined by residues Asp55H and Glu58H, on the complementarity determining regions (CDRs) of $m A b 2 G 10$. (A) Side and (B) front views of the predicted $m A b 2 G 10$ epitope on $m A b 2 C 7$ and the CDRs of $m A b 2 G 10$, shown in space filling representation and coloured according to solvent accessibility, decreasing in the order yellow, green, light blue, and dark blue. (C) Side and (D) front views of the trimolecular complex represented by its molecular surfaces and coloured according to electrostatic potential. Again, the electrostatic potential was computed by the program Swiss PDB-Viewer, ${ }^{9}$. which uses simple coulomb interaction. The mAb $2 \mathrm{C7}$ epitope predicted to be recognised by mAb $2 G 10$ consists of a positively charged protrusion (blue),

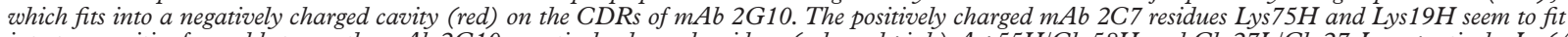
into two cavities formed between the $m A b 2 G 10$ negatively charged residues (coloured pink) Asp55H/Glu58H and Glu27L/Glu27cL, respectively. In (A) and $(C) m A b 2 G 10$ is pulled apart from the Der p 1-mAb $2 C 7$ complex and viewed from the side. In (B) and (D) each component is rotated $90^{\circ}$ towards the viewer.

mAb $2 \mathrm{C} 7$ residues Asp28H and $\mathrm{Asp} 53 \mathrm{H}$ on one side and Asp28H/Asp53H and Asp53L on the other side.

Figure 6 shows the predicted interaction surfaces within the trimolecular complex of Der p 1-mAb 2C7-mAb 2G10. Shape and charge complementarity was observed between the predicted epitope on $\mathrm{mAb} 2 \mathrm{C} 7$ and the CDRs of mAb 2G10. The mAb $2 \mathrm{C} 7$ epitope recognised by mAb $2 \mathrm{G} 10$ is formed by a positively charged protrusion defined by heavy chain residues within the FRW3 region; namely, Ser74-Gln81 and Lys19 from FRW1, which are complementary to a negatively charged surface on mAb 2G10 CDRs. The positively charged mAb $2 \mathrm{C} 7$ residues Lys $75 \mathrm{H}$ and Lys $19 \mathrm{H}$ seem to fit into two cavities formed between the mAb 2G10 negatively charged residues Asp55H/Glu58H and Glu27L/Glu27cL, respectively (fig 6). Furthermore, the epitope recognised by $\mathrm{mAb} 2 \mathrm{G} 10$ is located on the FRW region of $\mathrm{mAb} 2 \mathrm{C} 7$ and is away from the CDR residues that are thought to form the groove responsible for binding to Der $\mathrm{p} \mathrm{1.} \mathrm{As} \mathrm{expected,} \mathrm{the} \mathrm{location} \mathrm{of} \mathrm{the} \mathrm{mAb}$ 2C7 epitope recognised by mAb $2 \mathrm{G} 10$ does not appear to interfere with the binding of Der p 1 to $\mathrm{mAb} 2 \mathrm{C} 7$, which supports our previous experimental data showing that mAb $2 \mathrm{G} 10$ does not block the binding of Der $\mathrm{p} 1$ to $\mathrm{mAb}$ $2 \mathrm{C} 7 .^{2}$

\section{Discussion}

In this paper, we used the programs Swiss Model $^{9}{ }^{10}$ and Swiss PDB-Viewer ${ }^{9} 10$ to build a three dimensional model of a trimolecular complex consisting of Der p 1-mAb 2C7$\mathrm{mAb} 2 \mathrm{G} 10$. This task was facilitated by the availability of previously published experimetal data, which defined the $\mathrm{mAb} 2 \mathrm{C} 7$ epitope on Der p 1 (Leu147-Gln160), ${ }^{3}$ and which demonstrated that mAb 2G10 does not bind to the $\mathrm{CDR}$ regions of $\mathrm{mAb} 2 \mathrm{C} 7 .{ }^{2}$ This helped us to focus our efforts on the FRW regions of $\mathrm{mAb} 2 \mathrm{C} 7$ as the site of interaction with $\mathrm{mAb} 2 \mathrm{G} 10$. Investigation of shape and charge complementarity suggested that the $\mathrm{mAb} 2 \mathrm{C} 7$ epitope recognised by $\mathrm{mAb} 2 \mathrm{G} 10$ is distant from the mAb $2 \mathrm{C} 7 \mathrm{CDR}$ regions that are involved in Der p 1 binding. This means that Der $p 1$ and mAb $2 \mathrm{G} 10$ could engage $\mathrm{mAb} 2 \mathrm{C} 7$ simultaneously, which is in keeping 
with our previous experimental data showing that mAb 2G10 does not block the binding of Der p 1 to $\mathrm{mAb} 2 \mathrm{C} 7$. $^{2}$

Given that the anti-idiotype mAb 2G10 recognises FRW residues encoding human immunoglobulin $\mathrm{V}_{\mathrm{H}} 3$ and $\mathrm{V}_{\mathrm{H}} 4$ gene segments, ${ }^{2}$ it might be feasible to use this anti-idiotype in inhibition experiments to determine the influence of FRW regions of such antibodies on antigen binding. Furthermore, considering its broad $\operatorname{IgE}$ specificity, ${ }^{2}$ our anti-idiotype $\mathrm{mAb}$ 2G10 could potentially have immunomodulatory applications. For instance, a chimaeric human IgG version of $\mathrm{mAb} 2 \mathrm{G} 10$ might prove to be a useful molecule for binding to mast cell FceRI bound IgE, and in doing so co-ligating FceRI with FcyRIIb, which has been reported to be a negative regulator of type I allergic responses. ${ }^{45}$ Thus, having cloned and sequenced the variable region of $\mathrm{mAb} 2 \mathrm{G} 10$, it will now be relatively straightforward to produce a chimaeric human IgG construct of it. This will provide new opportunities for investigating the potential ability of this antiidiotype to modify IgE mediated allergic responses.

Clearly, the results obtained here represent only an approximation, but nevertheless they provide a rare insight into how a clinically important allergen (Der p 1) might bind to an antibody representative of human $\operatorname{IgE}(\mathrm{mAb}$ 2C7) while complexed with an anti-idiotype (mAb 2G10).

This work was supported by the BBSRC (grant T03598). PBF is funded by a University of Nottingham International Office scholarship and by CAPES-Governo Federal do Brasil (Processo BEX 1176/98-6).

1 McElveen JE, Clark MR, Smith SJ, et al. Primary sequence and molecular model of the variable region of a mouse monoclonal anti-Der p 1 antibody showing a similar epitope specificity as human IgE. Clin Exp Allergy 1998;28:1427-34.

2 McElveen JE, Furtado PB, Smith SJ, et al. Characterisation of a mouse monoclonal anti-idiotype reactive with a globulins. $\mathcal{F}$ Clin Pathol: Mol Pathol 2000;53:77-82.

3 Furmonaviciene R, Tighe PJ, Clark MR, et al. The use of phage-peptide libraries to define the epitope specificity of phage-peptide libraries to define the epitope specificity of a mouse monoclonal anti-Der p1 antibody representative of a major component of the human immunoglobulin E an

4 Riechmann L, Clark MR, Waldmann H, et al. Reshaping human antibodies for therapy. Nature 1988;332: 323-7

5 Evans SV, Rose DR, To R, et al. Exploring the mimicry of polysaccharide antigens by anti-idiotypic antibodies. The crystallization, molecular replacement, and refinement to $2.8 \AA$ A resolution of an idiotope-anti-idiotope Fab complex and of the unliganded anti-idiotope Fab. $f \mathrm{Mol}$ Biol 1994;241:691-705.

6 Fields BA, Goldbaum FA, Ysern X, et al. Molecular basis of antigen mimicry by an anti-idiotype. Nature 1995;374:73942 .

7 Bentley GA, Boulot G, Riottot MM, et al. Threedimensional structure of an idiotope-anti-idiotope complex. Nature 1990;348:254-7.

8 Ban N, Escobar C, Garcia R, et al. Crystal structure of Ban N, Escobar C, Garcia R, et al. Crystal structure of idiotype-anti-idiotype

9 Guex N, Peitsch MC. SWISS-MODEL and the Swiss-Pdb Viewer: an environment for comparative protein modelling. Electrophoresis 1997;18:2714-23.

10 Peitsch MC. Pro-Mod and Swiss-Model: internet-based tools for automated comparative protein modelling. Biochem Soc Trans 1996;24:274-9.

11 Kettleborough CA, Saldanha J, Ansell KH, et al. Optimization of primers for cloning libraries of mouse immunoglobulin genes using the polymerase chain reaction. Eur $\mathcal{F}$ Immunol 1993;23:206-11.

12 LeFranc M-P, Giudicelli V, Ginestoux C, et al. IMGT, the international ImMunoGeneTics database. Nucleic Acids international ImMun $1999 ; 27: 209-12$.
13 Kabat EA, Wu TT, Reid-Miller M, et al. Sequences of proteins of immunological interest, 5th ed. Bethesda: US Department of immunological interest, 5 th ed. Bethesd
of Health and Human Services, 1991.

14 Cheetham GM, Hale G, Waldmann A, et al. Crystal structures of a rat antibody CD52 (CAMPATH-1H) therapeutic antibody $\mathrm{Fab}$ fragment and its humanised counterpart. F Mol Biol 1998;284:85-99.

15 Bothwell ALM, Paskind M, Reth M, et al. Heavy chain variable region contribution to the b-NP family of antibodies: somatic mutation evident in a gamma-2a variable region. Cell 1981;24:625-37.

16 Hamlyn PH, Gait MJ, Milstein C. Complete sequence of an immunoglobulin mRNA using specific priming and the dideoxynucleotide method of RNA sequencing. Nucleic Acids Res 1981;9:4485-94.

17 Derrick JP, Wigley DB. The third IgG-binding domain from streptococcal protein $\mathrm{G}$. An analysis by X-ray crystallography of the structure alone and in a complex with Fab. $\mathcal{F} \mathrm{Mol}$ Biol 1994;243:906-18.

18 Berman HM, Westbrook J, Feng Z, et al. The protein databank. Nucleic Acids Res 2000;28:235-42.

9 Austin EB, Robins RA, Durrant LG, et al. Human monoclonal anti-idiotypic antibody to the tumourassociated antibody 791T/36. Immunology 1989;67:52530.

20 Potter KN, Yucheng L, Capra JD. Staphyloccocal protein A simultaneously interacts with framework region 1, complementarity-determining region 2 and framework region 3 on human VH3-encoded Igs. $f$ Immunol 1996;157:2982-8.

21 Sanz I, Capra DJ. Vk and Jk gene segments of A/J Ars-A antibodies: somatic recombination generates the essential Proc Natl Acad Sci U S A 1987;84:1085-9.

22 Spellerberg MB, Chapman CJ, Mackridge I, et al. Dual recognition of lipid A and DNA by human antibodies encoded by the Vh4-21 gene: a possible link between infection and lupus. Hum Antibodies Hybridomas 1995;6:52-6.

23 Williams SC, Winter G. Cloning and sequencing of human immunoglobulin $\mathrm{V} \lambda$ gene segments. Eur $\mathcal{f}$ Immunol 1993;23:1456-61

24 Sakano H, Maki R, Kurosawa Y, et al. Two types of somatic recombination are necessary for the generation of complete immunoglobulin heavy chain genes. Nature 1980;286:67683.

25 Potter M, Newell JB, Rudikoff R, et al. Classification of mouse Vk groups based on the partial amino acid sequence to the first invariant tryptophan: impact of 14 new sequences from IgG myeloma proteins. Mol Immunol 1982; 19:1619-30

26 Eigenbrot C, Randal M, Presta L, et al. X-ray structures of the antigen-binding domains from three variants of humanised anti-P185HER2 antibody 4D5 and comparison with molecular modelling. F Mol Biol 1993;229:96995 .

27 Hougs L, Juul L, Svejgaard A, et al. Structural requirements of the major protective antibody to Haemophilus influenzae type b. Infect Immun 1999;67:2503-14.

28 Saul FA, Poljak RJ. Crystal structure of human immunoglobulin fragment Fab New refined at 2.0 angstrom resolution. Proteins Structure Function and Genetics 1992;14:36371 .

29 Celikel R, Varuguese KI. Crystal structure of the von Willebrand factor A1 domain in complex with the function blocking NMC-4Fab. Nat Struct Biol 1998;5:189-94.

30 Lescar J, Stouracova R, Riottot M-M, et al. Threedimensional structure of a Fab-peptide complex: structural antibody. $\mathcal{F}$ Mol Biol 1997;267:1207-22

31 Banfield MJ, King DJ, Mountain A, et al. VL:VH domain rotations in engineered antibodies: crystal structures of the Fab fragments from two murine anti-tumour antibodies and their engineered human constructs. Proteins Structure Function and Genetics 1997;29:161-71.

32 Topham CM, Srinivasan N, Thorpe CJ, et al. Comparative modelling of major house dust mite allergen Der $\mathrm{p} 1$ : structure validation using an extended environmental amino acid propensity table. Protein Eng 1994;7:869-94.

33 Ghiara JB, Stura EA, Stanfield RL, et al. Crystal structure of the principal neutralization site of HIV-1. Science 1994;264: $82-5$

34 Stanfield RL, Takimoto-Kamimura M, Rini J, et al. Major antigen-induced domain rearrangements in an antibody. Structure 1993;1:83-93.

35 Evans SV, Sigurskjold BW, Jennings HJ, et al. Evidence for the extended helical nature of polysaccharide epitopes. The $2.8 \AA$ resolution structure and thermodynamics of ligand binding of an antigen binding fragment specific for binding of an antigen binding fragment specific for 44 .

36 Lescar J, Pellegrini M, Souchon H, et al. Crystal structure of cross-reaction complex between Fab F9.13.7 and guinea fowl lysozyme. F Biol Chem 1995;270:18067-76.

37 Clothia C, Lesk AM, Tramontano A, et al. Conformation of immunoglobulin hypervariable regions. Nature 1989;342: $877-83$

38 Clothia C, Lesk AM. Canonical structures for the hypervariable regions of immunoglobulins. $7 \mathrm{Mol}$ Biol 1987;196:901-17.

39 Tramontano A, Clothia C, Lesk AM. Framework residue 71 is a major determinant of the position and conformation of the second hypervariable region in the $\mathrm{VH}$ domains of immunoglobulins. F Mol Biol 1990;215:175-82. 
40 Sheriff S, Silverton EW, Padlan EA, et al. Threedimensional structure of an antibody-antigen complex. dimensional structure of an antibody-a
Proc Nat Acad Sci U S A 1987;84:8075-9.

41 Colman PM, Laver WG, Varghese JN, et al. Threedimensional structure of a complex of antibody with influenza virus neuraminidase. Nature 1987;326:358-63.

42 Satow Y, Cohen GH, Padlan EA, et al. Phosphocholine binding immunoglobulin Fab McPC603. An x-ray diffraction study at $2.7 \mathrm{~A}$. $\mathcal{F} \mathrm{Mol} \mathrm{Biol} \mathrm{1986;190:593-7.}$

43 Shirai H, Kidera A, Nakamura H. Structural classification of CDR-H3 in antibodies. FEBS Lett 1996;399:1-8.
44 Schroeder HW, Jr, Hilson JL, Perlmutter RM. Structure and evolution of mammalian VH families. Int Immunol 1990;2: 41-50.

45 Daeron M, Malbec O, Latour S, et al. Regulation of high-affinity IgE receptor-mediated mast cell activation by murine low-affinity IgG receptors. $\mathcal{F}$ Clin Invest 1995;95: $577-85$.

46 Takai T, Ono M, Hikida M, et al. Augmented humoral and anaphylactic responses in Fc $\gamma$ RII-deficient mice. Nature 1996;379:346-9. 